\title{
Gene flow is maintained by polyandry and male dispersal in the army ant Eciton burchellii
}

\author{
Rodolfo Jaffé • Robin F. A. Moritz • \\ F. Bernhard Kraus
}

Received: 16 June 2008/Accepted: 23 September 2008/Published online: 27 January 2009

(C) The Society of Population Ecology and Springer 2009

\begin{abstract}
The combination of haplodiploidy, complementary sex determination and eusociality constrains the effective population size $\left(N_{\mathrm{e}}\right)$ of social Hymenoptera far more than in any other insect group. Additional limitations on $N_{\mathrm{e}}$ occur in army ants since they have wingless queens and colony fission, both of which are factors causing restricted maternal gene flow and high population viscosity. Therefore, winged army ant males gain a particular significance to ensure dispersal, facilitate gene flow and avoid inbreeding. Based on population genetic analyses with microsatellite markers, we studied a population of the Neotropical army ant Eciton burchellii, finding a high level of heterozygosity, weak population differentiation and no evidence for inbreeding. Moreover, by using sibship reconstruction analyses, we quantified the actual number of male contributing colonies represented in a queen's mate sample, demonstrating that, through extreme multiple mating, the queens are able to sample the genes of males from up to ten different colonies, usually located within an approximate radius of $1 \mathrm{~km}$. We finally correlated the individual mating success of each male contributing colony with the relative
\end{abstract}

Electronic supplementary material The online version of this article (doi:10.1007/s10144-008-0133-1) contains supplementary material, which is available to authorized users.

R. Jaffé $(\square)$ · R. F. A. Moritz · F. B. Kraus

Institut für Biologie, Martin-Luther-Universität

Halle-Wittenberg, Hoher Weg 4,

06099 Halle (Saale), Germany

e-mail: rodolfo.jaffe@zoologie.uni-halle.de

F. B. Kraus

Departamento Entomología Tropical, El Colegio de la Frontera

Sur (ECOSUR), Carr. Antiguo Aeropuerto km 2.5.,

C.P. 30700 Tapachula, Chiapas, Mexico siring success of individual males and found a significant colony-dependent male fitness component. Our results imply that the dispersal and mating system of these army ants seem to enhance gene flow and minimise the deleterious effects associated with small effective population size.

Keywords Dependent colony foundation - Eciton . Multiple mating · Nuptial flights .

Sibship reconstruction analysis $\cdot$ Social insects

\section{Introduction}

Social insects (ants, bees, wasps and termites) dominate terrestrial ecosystems. They are among the main predators of other arthropods, pollinate the majority of flowering plants and are important food sources for many other animals (Wilson 1971). Within most social Hymenoptera, however, the combination of eusociality, haplodiploidy and complementary sex determination seriously constrains their effective population size $\left(N_{\mathrm{e}}\right)$ far more than in any other insect group (Hedrick and Parker 1997; Chapman and Bourke 2001; Packer and Owen 2001). $N_{\mathrm{e}}$, the size of a genetically ideal population that has the same rate of heterozygosity loss as an actual population under consideration, is mostly limited by the abundance of the rare sex. Eusocial Hymenoptera usually have one or few reproductive females per colony (the queens) and, therefore, have smaller effective population sizes than solitary species with a larger number of reproductive individuals per unit area (Wilson 1963; Chapman and Bourke 2001). The effective population size of haplodiploid organisms is given by the following equation (Wright 1933): 
$N_{\mathrm{e}}=\frac{9 N_{\mathrm{f}} N_{\mathrm{m}}}{\left(2 N_{\mathrm{f}}+4 N_{\mathrm{m}}\right)}$

where $N_{\mathrm{f}}$ is the number of breeding females and $N_{\mathrm{m}}$ is the number of breeding males. In haplodiploids, the haploid condition of males reduces the number of copies of a given allele in the population. Therefore, under equal sex ratios, the effective population size of haplodiploids is threequarters the effective size of populations of diploid organisms (Hedrick and Parker 1997). Additionally, the usual sex determination through the complementary action of specific sex alleles at the autosomal complementary sex determination (CSD) locus inevitably results in a fraction of unviable or effectively sterile diploid males in the population. The production of diploid males not only limits colony growth (Van Wilgenburg et al. 2006) but also biasses the effective breeding sex ratio in favour of haploid males, further reducing $N_{\mathrm{e}}$ (Zayed 2004). The sum of these factors seriously constrains $N_{\mathrm{e}}$, making hymenopteran populations susceptible to genetic drift and inbreeding, and hence, more prone to accumulating deleterious alleles. Therefore, strong selective pressures are expected to promote dispersal abilities and promiscuous mating behaviour to avoid the deleterious effects associated with a reduced $N_{\mathrm{e}}$ (Keller and Passera 1993; Nunney 1993; Crozier and Pamilo 1996).

Dispersal in eusocial Hymenoptera is mainly determined by the flight ability of the sexual reproductives (Peeters and Ito 2001). In ants, where workers have permanently lost their wings, gene flow is determined by the mode of colony foundation (Bourke and Franks 1995). The foundation of new ant colonies can either be done by the queen(s) alone through independent colony foundation (ICF) or by the queen(s) along with a group of workers, which is called dependent colony foundation (DCF). While in most species with ICF the winged queens are able to fly away from their natal nest, DCF restricts dispersal to the 'walking distance' of workers (Hölldobler and Wilson 1990). Hence, DCF imposes greater limitations to gene flow than ICF, resulting in restricted maternal gene flow and greater population viscosity (Liautard and Keller 2001; Doums et al. 2002; Seppä et al. 2006). Additionally, the ecological constraints on effective dispersal and independent breeding responsible for DCF seem to be associated with polygyny (the occurrence of multiple queens in one colony), whereas monogynous species (with colonies headed by a single queen) generally exhibit ICF (Bourke and Heinze 1994; Pedersen and Boomsma 1999; Sundström et al. 2005).

Army ants constitute a remarkable exception to this general pattern because they exhibit DCF but are usually headed by a single, multiply mated (polyandrous) queen (Schneirla 1971; Kronauer et al. 2007). They are a large group of mostly tropical and subterranean ants characterised by "the army ant adaptive syndrome" (Gotwald 1995), the combination of group predation and nomadism. The enhanced group predation efficiency that results from very large colonies reproducing through colony fission probably selected for the loss of wings in army ant queens, at the expense of higher dispersion ability. In addition, as an inevitable consequence of colony fission, army ants exhibit extremely male biassed sex ratios, enhancing the opportunity for random genetic drift and making this species more susceptible to inbreeding (Hartl and Clark 2007). Army ants, thus, represent an excellent test case for the efficiency of dispersal and mating strategies in enhancing gene flow (Hölldobler and Bartz 1985; Gadagkar 1991).

Although a substantial number of studies have shed light on the ecology and behaviour of army ants (e.g., Schneirla 1971; Gotwald 1995), only the recent development of genetic markers has allowed unknown aspects of their reproductive biology and social organisation to be revealed (Kronauer et al. 2006a, 2007; Jaffé et al. 2007). A recent study showed that a Panamanian population of the army ant Eciton burchellii Mayr exhibits high nuclear gene flow, in spite of restricted maternal (mitochondrial) gene flow (Berghoff et al. 2008). Obviously, male-mediated gene flow must be important in these ants. Yet, estimates of male dispersal distance in army ants are still lacking, probably because of the difficulties involved in capturing, identifying and following army ant males. Likewise, the actual number of colonies contributing to the male population and their individual mating success, essential parameters for understanding the population structure of these ants, are still unknown. Here, we address these aspects in a Mexican population of the army ant $E$. burchellii. By genotyping enough worker offspring of the highly polyandrous Eciton queens (Kronauer et al. 2006b), which can be easily collected in the field, it is possible to deduce the genotypes of all the siring males of a particular colony. Based on these inferred male genotypes, we reconstructed the genotypes of their maternal queens, quantifying the number of colonies from which these males came. We then correlated the individual mating success of each male contributing colony with the relative siring success of individual males, testing for a colony-dependent male fitness component. Finally, based upon the number of male contributing colonies represented in a queen's mate sample, we estimated the male flight distance and the effective number of breeding individuals within a queen's mating area. We discuss the implications of our findings in the light of other recent contributions. 


\section{Materials and methods}

\section{Sampling}

Eciton burchellii males are difficult to collect in the field because they are only produced once per year and live for a short period of time (Gotwald 1995). The queens, however, are highly polyandrous, mating with up to 25 different males (Denny et al. 2004b). Taking advantage of this mating system, we used four E. burchellii queens (Q1, Q2, Q3 and Q4) found near Tapachula, Chiapas, Mexico, to obtain a large sample of males. By genotyping enough worker offspring from a single queen, it is possible to deduce the genotypes of all her mates, hence, obtaining a sample of male genotypes without having to collect and genotype the males directly. Q1, Q2 and Q3 were located in the surroundings of Cacahoatán $\left(14^{\circ} 59^{\prime} 48.59^{\prime \prime} \mathrm{N}\right.$, $\left.92^{\circ} 09^{\prime} 54.25^{\prime \prime} \mathrm{W}\right)$, while Q4 was found near Unión Juarez, $12 \mathrm{~km}$ apart and $800 \mathrm{~m}$ higher than Cacahoatán $\left(15^{\circ} 01^{\prime} 57.31^{\prime \prime} \mathrm{N}, 92^{\circ} 06^{\prime} 22.98^{\prime \prime} \mathrm{W}\right)$. Q2 and Q3 were found in the same location (hence, estimated to be $50 \mathrm{~m}$ apart from each other) and about $500 \mathrm{~m}$ from the location where Q1 was found. About 500 workers from each colony were preserved in $95 \%$ ethanol and kept at $-20^{\circ} \mathrm{C}$ for subsequent genetic analyses.

\section{Genotyping}

We genotyped a total of 1,107 E. burchellii workers. DNA extractions were performed using a Chelex protocol (Walsh et al. 1991). Genotyping was done using eight polymorphic microsatellite markers (Denny et al. 2004a): Eb04, Eb10, Eb14, Eb21, Eb24, Eb25, Eb42 and Eb51.
The microsatellite target sequences were amplified by polymerase chain reactions (PCR) using fluorescent tagged primers. PCR products were then run in a MegaBACE 1000 capillary sequencer to determine allele sizes and allele calling was checked by eye using the Genetic Profiler software (Amersham Biosciences). From the eight microsatellites initially employed, Eb04 and Eb14 had to be discarded because of poor amplifications and a high frequency of null alleles, respectively. Employing the remaining six loci and excluding those individuals with less than three successfully amplified loci in all subsequent analyses (363 individuals excluded, see Table 1 for the final sample sizes), we obtained a mean non-detection error (the probability of not identifying a siring male because it shares the same allele combination with another male by chance) of $2.09 \times 10^{-4}$ (Boomsma and Ratnieks 1996).

Male genotype deduction, genetic diversity measures and population differentiation

Following Kronauer et al. (2006b), we first deduced the genotypes of the queens and their mates by running MateSoft version 1.0 (Moilanen et al. 2004) with all known alleles at equal frequencies. In some cases, MateSoft returns two or more alternative genotypes accompanied by their respective weighted probability, which is calculated based on the allele frequencies initially given. We therefore, computed an unbiassed estimate of the allele frequencies based on all inferred alternative genotypes and employed them to run MateSoft once again, replacing the original uninformative background frequencies. This procedure allowed us to determine the most probable genotypes of the siring males of each particular colony.

Table 1 Mating frequency, relatedness, genetic diversity measures and sibship reconstruction results from a sample of 73 males deduced from genotyping 744 worker offspring of four Eciton burchellii queens (Q1, Q2, Q3, Q4)

\begin{tabular}{lrlllllllll}
\hline Queen & $n_{\mathrm{W}}$ & $n_{\mathrm{M}}$ & $m_{\mathrm{e}}$ & $r_{\mathrm{ww}}$ & $n_{\mathrm{a}}$ & $H_{\mathrm{E}}$ & $n_{\mathrm{RQ}}$ & $n_{\mathrm{EQ}}$ & $N_{\mathrm{e}}^{\prime}$ \\
\hline Q1 & 264 & 25 & 17.83 & 0.32 & 8.00 & 0.83 & 12 & 12.63 & 1.07 & 21.77 \\
Q2 & 123 & 13 & 10.33 & 0.34 & 6.00 & 0.76 & 7 & 7.58 & 0.83 & 12.41 \\
Q3 & 86 & 16 & 13.33 & 0.31 & 5.83 & 0.76 & 9 & $9.61^{\mathrm{b}}$ & 0.93 & 15.80 \\
Q4 & 271 & 19 & 11.40 & 0.18 & 6.33 & 0.81 & 8 & 8.39 & 0.87 & 14.87 \\
Total & 744 & 73 & $12.68 \pm 0.46$ & $0.29 \pm 0.01$ & $6.54 \pm 0.99$ & $0.79 \pm 0.04$ & $9.00 \pm 0.36$ & $9.55 \pm 0.37$ & $0.92 \pm 0.02$ & $16.21 \pm 0.66$
\end{tabular}

$n_{\mathrm{W}}$ is the number of genotyped workers with more than three successfully amplified loci, $n_{\mathrm{M}}$ the number of siring males (observed paternity), $m_{\mathrm{e}}$ the effective mating frequency following Nielsen et al. (2003) and $r_{\mathrm{ww}}$ is the intracolonial worker-worker regression relatedness. Genetic diversity measures are given as the mean number of alleles per locus $\left(n_{\mathrm{a}}\right)$ and Nei's expected heterozygosity $\left(H_{\mathrm{E}}\right)$. The results from the sibship reconstruction analyses are shown as the number of reconstructed queens $\left(n_{\mathrm{RQ}}\right)$ and the number of expected queens after correcting for sample size $\left(n_{\mathrm{EQ}}\right)$. The radius of the queen's mating area is presented as an estimate for the maximal male flight distance (FD), while $N_{\mathrm{e}}{ }^{\prime}$ represents the effective number of breeding individuals within a queen's mating area. The totals are given as sums for $n_{\mathrm{W}}$ and $n_{\mathrm{M}}$, harmonic mean \pm standard error from jack-knifing over samples for $m_{\mathrm{e}}$, arithmetic mean $\pm \mathrm{SD}$ for the number of alleles and heterozygosity, and arithmetic mean $\pm \mathrm{SE}$ from jack-knifing over samples for $r_{\mathrm{ww}}$, queen number, flight distance and $N_{\mathrm{e}}{ }^{\prime}$

${ }^{a}$ Flight distance based on a density of 3.5 colonies $/ \mathrm{km}^{2}$ (Franks 1982)

b The number of siring males were not binomially distributed among the reconstructed queens, causing a slight underestimation of the nonsampling error in this particular sample 
Genetic diversity measures (mean number of alleles per locus and Nei's expected heterozygosity) were then computed, taking the genotypes of each queen and her mates as a sample set from a single location [see S1 in Electronic Supplementary Material (ESM)]. Based on these sample sets, we also estimated the overall and pairwise standardised $F_{\mathrm{ST}}$ values (Hedrick 2005) and tested them against zero using the standard deviation from jack-knifing over the loci. All analyses were performed using FSTAT 2.9.3.2 (Goudet 2001). In order to determine the incidence of type II errors in our analyses (the probability of failing to detect population differentiation), we performed a power analysis using STATISTICA v6.0 (StatSoft Inc.).

\section{Relatedness and inbreeding}

Using Relatedness v5.0.8 (Queller and Goodnight 1989), we estimated the regression genetic relatedness between the workers of each colony $\left(r_{\mathrm{ww}}\right)$, between the queens and their mates $\left(r_{\mathrm{qm}}\right)$, between the mates of each queen $\left(r_{\mathrm{mm}}\right)$ and between the mates of different queens or single-cohort males $\left(r_{\mathrm{cc}}\right)$. Under no inbreeding, the regression workerworker relatedness $\left(r_{\mathrm{ww}}\right)$ should be identical to the pedigree relatedness $\left(g_{\mathrm{ww}}\right)$ given by Pamilo (1993):

$g_{\mathrm{ww}}=0.25+\frac{0.5}{m_{\mathrm{e}}}$

where $m_{\mathrm{e}}$ is the effective paternity (Nielsen et al. 2003). We therefore, compared these two estimates in each colony (using the standard deviation of $r_{\mathrm{ww}}$ obtained from jackknifing over loci) and over all colonies (through a nonparametric pairwise test). Finally, the overall means of all pairwise $r_{\mathrm{qm}}, r_{\mathrm{mm}}$ and $r_{\mathrm{cc}}$ were tested against zero.

\section{Sibship reconstruction analyses}

Since males are produced parthenogenetically and, hence, only carry alleles from their mother, it is possible to assign them into specific colonies. In order to do this, the genotypes of all siring males from each particular colony were introduced into Colony 1.3 (Wang 2004), a software allowing the reconstruction of full and half-sibships based on the population allele frequencies (ESM, S2-S5). The method follows a maximum likelihood approach and assumes unlinked loci. As other sibship reconstruction methods, the Colony software package exhibits two main limitations (Wang 2004), namely, that an insufficient number of informative loci results in a lack of accuracy and that it is sensitive to genotyping errors, such as missamplifications or allelic dropouts. These constraints, however, should have caused no important inaccuracies in our results: (1) by employing all established microsatellite markers for E. burchellii, we maximised the power of the analysis and (2) genotyping errors were rare in our input files, since each paternal genotype was confirmed by many worker genotypes. Colony is able to account for genotyping errors during the sibship reconstruction analysis, but a probability for the incidence of such errors in each loci must be given. Running Colony with typing error probabilities of $P=0.05$ for each loci yielded similar results, confirming their low impact on our analysis. Aiming to further increase the precision of our analyses, we repeated each run five times, employing different random seeds. Obtaining exactly the same result in all runs assured us that the method converged for our data sets. As a measurement of the accuracy of each sibship reconstruction analysis, we report the log-likelihood of the best configuration.

Estimation of male flight distance and effective number of breeding individuals

Due to the highly polyandrous behaviour of Eciton queens, we gained access to the genotypes of many males from different sampling locations. This sampling approach is, however, limited by the queen's capacity to gather mates from all of the male-producing colonies within recruitment distance, and, therefore, we need to correct for the nonsampling error. Based on a fitted binomial distribution of the siring males among the reconstructed queens (Fig. 1), we estimated the frequency of male contributing colonies unrepresented in each sample (see Moritz et al. 2007). By adding these non-detected sire colonies to the initial number of reconstructed queens $\left(n_{\mathrm{RQ}}\right)$, we obtained the number of expected queens in each area $\left(n_{\mathrm{EQ}}\right)$.

In order to estimate the male flight distance, we first determined the mating area $(A)$ of each of our queens, based on the following relation:

$A=\frac{n_{\mathrm{EQ}}}{\rho}$

where $n_{\mathrm{EQ}}$ is the number of expected queens in the area and $\rho$ is the density of colonies per square kilometre. Following a similar approach as that described by Franks (1982) to census the number of $E$. burchellii colonies, we obtained a rough density estimate of $2-3$ colonies $/ \mathrm{km}^{2}$. The accuracy of this density estimate, however, may not be very high since: (1) the fragmentation of land by private coffee plantations is likely to result in a highly patchy distribution of army ants in our sampling locations and (2) the delimitation of the area occupied by our population is more or less arbitrary. We therefore, decided to base our calculations on the density estimate reported by Franks (1982) $\left(\rho=3.5\right.$ colonies $\left./ \mathrm{km}^{2}\right)$. This is a more accurate estimate since it is based on a population occupying an undisturbed primary rain forest, restricted to a single island (Barro 
Fig. 1 Distribution of the siring males from four Eciton burchellii colonies $(\mathrm{Q} 1, \mathrm{Q} 2, \mathrm{Q} 3$ and Q4) among their reconstructed maternal queens (or colonies from where they came). While each bar illustrates the number of reconstructed queens represented by a given number of males, the dashed lines show the expected binomial distribution (sample sizes are $n_{1}=25 ; n_{2}=13 ; n_{3}=16$ and $n_{4}=19$ males)
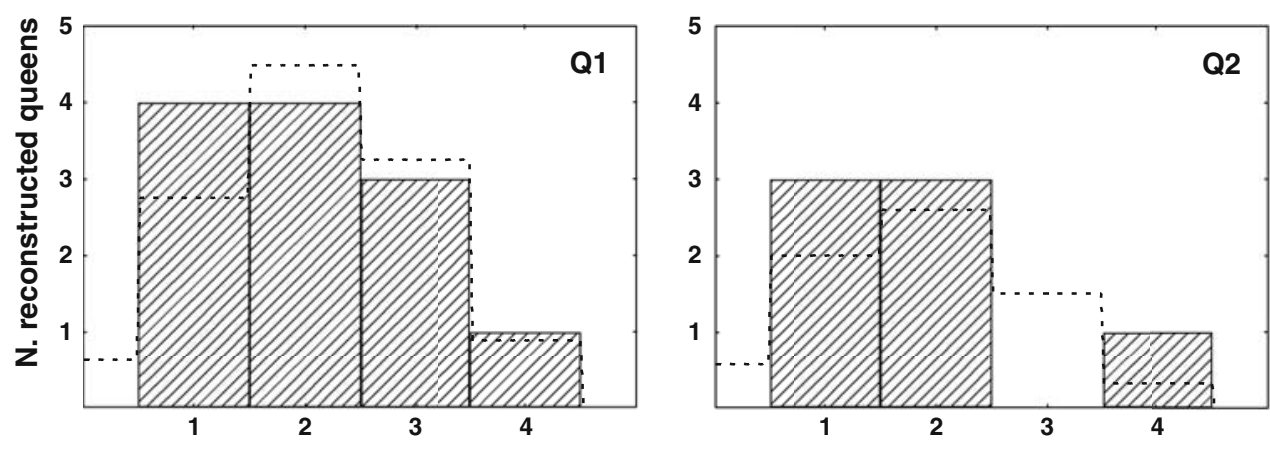

N. siring males
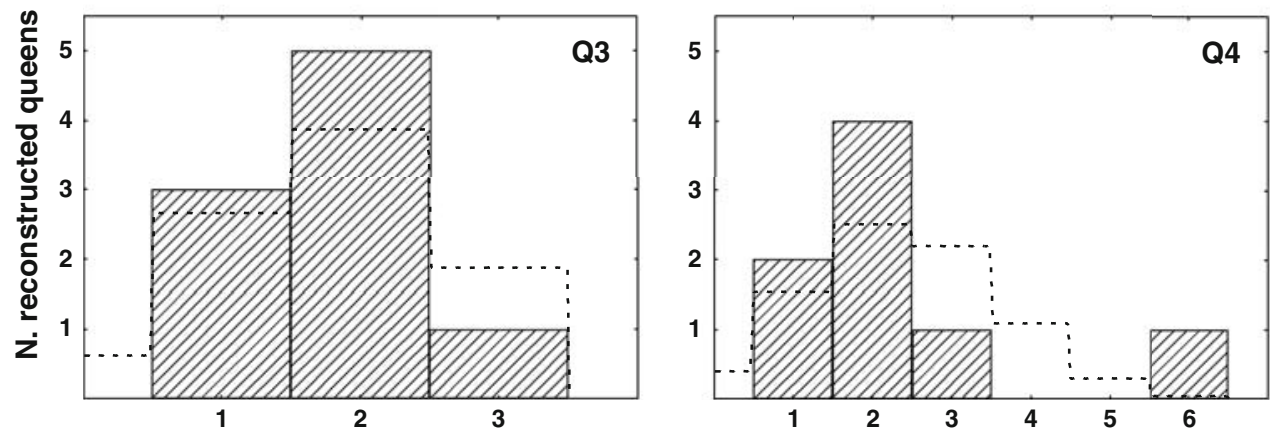

N. siring males
Colorado Island, Panama). Based on this density, the maximum male flight distance was then calculated as the radius of $A$, assuming it to have a circular shape (Chapman et al. 2003). Similar approaches based on genetic markers were previously employed to estimate the foraging distances of bumblebees (Chapman et al. 2003; Darvill et al. 2004; Knight et al. 2005) and the colony densities of honeybees (Kraus et al. 2005; Moritz et al. 2007).

Because we had no information about the gene flow to or from the population where our samples were collected, we could not estimate its effective population size (Wang 2005). We therefore, calculated the effective number of breeding individuals within a queen's mating area $\left(N_{\mathrm{e}}^{\prime}\right)$ following Eq. 1 and based on the results generated in the sibship reconstruction analyses, with $N_{\mathrm{f}}=n_{\mathrm{RQ}}$ and $N_{\mathrm{m}}=$ the observed paternity of each colony.

Testing for a colony-dependent male fitness component

In order to test whether the reconstructed queens were contributing males to different colonies, we first extracted the reconstructed queen genotypes from each independent sibship reconstruction analysis (ESM, S2-S5). By comparing these queen genotypes, we were able to check whether different siring male samples allowed the reconstruction of identical queen genotypes. We then analysed the relationship between colony mating success and the siring success of individual males. Given that males mate only once, the mating success of a colony depends on the number of successfully mated males produced. We therefore, used the number of siring males assigned as sons of a specific reconstructed queen as an indirect measure of colony mating success. It was, however, not possible to estimate the absolute reproductive success of reconstructed queens, since we had no information about the total number of successfully mated males that they produced. The siring success of individual males was calculated based on the deviation between the number of workers sired by each male and that expected under an equal distribution of patrilines within the worker offspring of a given queen. Therefore, we measured the relative siring success $S$ of male $j$ following:

$S_{j}=\frac{W_{j}}{n_{\mathrm{w}}}-\frac{1}{n_{\mathrm{m}}}$

where $W_{j}$ is the number of offspring sired by male $j, n_{\mathrm{w}}$ the number of workers sampled and $n_{\mathrm{m}}$ is the observed mating frequency of the particular queen (Kraus et al. 2003). In order to test for a possible correlation between colony mating success and the siring success of individual males, we performed a Spearman rank correlation. The mating success of reconstructed queens and the siring success of individual males are two independent measures (obtained from two different generations), and, hence, no correlation should be expected in the absence of a colony-dependent male fitness component. 


\section{Results}

Paternity, genetic diversity and population differentiation

Based on a sample of 744 genotyped workers showing at least three successfully amplified loci, we were able to deduce the genotype of 73 siring males (Table 1). On average, ten worker genotypes confirmed each of the siring male genotypes. We found that E. burchellii queens mated with 13-25 males (arithmetic mean $\pm \mathrm{SE}$ $18.3 \pm 0.9$ ), with an effective number of matings ranging between 10.3 and 17.8 (harmonic mean $\pm \mathrm{SE}$ $12.7 \pm 0.5$ ), confirming earlier estimates (Kronauer et al. 2006b).

The mean number of alleles per locus and expected heterozygosity ranged from 3 to 10 and from 0.5 to 0.9 , respectively (mean values given in Table 1). Population differentiation in the study area was weak (Table 2), with an overall $F_{\mathrm{ST}}=0.06$, which is not significantly larger than zero $(t=0.97 ; d f=5$; one-tailed $P>0.1$ ). Based on the six loci employed and the current data set, the power of this analysis was estimated to be $80 \%$.

\section{Relatedness and inbreeding}

Intracolonial regression relatedness did not differ from the pedigree relatedness, neither when comparing these estimates in each individual colony (single-sample $t$-tests with $5 d f: t=0.19, t=0.38, t=0.16$ and $t=1.18$ for Q1, Q2, Q3 and Q4, respectively; $P>0.2$ in all cases) nor over all colonies (Wilcoxon matched pairs test: $Z=0.37$; $P=0.72$; Table 1), confirming the assumption of no inbreeding, i.e. zero relatedness between male and female parents. For instance, the mean relatedness between the queens and their mates was negative (overall mean $\pm \mathrm{SD}$ $r_{\mathrm{qm}}=-0.10 \pm 0.17 ;$ significantly smaller than zero $t=-4.82 ; d f=72 ; P<0.001)$, indicating a very low

Table 2 Pairwise $F_{\mathrm{ST}}$ values based on the genotypes of four $E$. burchellii queens and their mates (see S1)

\begin{tabular}{lllll}
\hline$F_{\text {ST }}$ & $P$ & & & \\
\cline { 2 - 5 } & Q1 & Q2 & Q3 & Q4 \\
\hline Q1 & - & 0.30 & 0.26 & 0.03 \\
Q2 & 0.08 & - & 0.27 & 0.28 \\
Q3 & 0.04 & 0.08 & - & 0.21 \\
Q4 & 0.06 & 0.05 & 0.07 & - \\
\hline
\end{tabular}

$F_{\text {ST }}$ values are given on the lower portion of the table, while the onetailed significance levels of single-sample $t$-tests are shown on the upper portion probability of recent coalescence between the queens and their mates relative to the average probability for all considered individuals in the population (Konovalov and Heg 2008). Some of the mates of each queen were found to be related (overall mean $\pm \mathrm{SD} r_{\mathrm{mm}}=0.05 \pm 0.23$; significantly larger than zero; $t=5.39 ; d f=72 ; P<0.001)$. However, when excluding the pairwise relatedness between brother males based on the results obtained in the sibship reconstruction analyses, the overall relatedness between the mates of each queen was not significantly larger than zero $\left(r_{\mathrm{mm}}=0.01 \pm 0.20 ; t=1.44 ; d f=72\right.$; $P=0.08)$. Likewise, single-cohort males were not related to other cohorts of males $\left(r_{\mathrm{cc}}=-0.03 \pm 0.19\right.$; significantly smaller than zero; $t=-7.38 ; d f=72 ; P<0.001$; see S6 in ESM).

Sibship reconstruction, male flight distance and effective number of breeding individuals

Given that population differentiation was weak, we pooled all of the sample sets to estimate the population-wide allele frequencies (S1). Based on these population-wide allele frequencies, we were able to reconstruct a mean $\pm \mathrm{SE}$ of $9.0 \pm 0.36$ male contributing queens per colony (loglikelihood for best configuration ranging from -254 to -134; see S2-S5). After correcting for sample size, we obtained a mean number of expected colonies of $9.6 \pm 0.4$, resulting in a queen's mating area of $A=2.7 \pm 0.1 \mathrm{~km}^{2}$ and a maximal male flight distance of $r=0.92 \pm 0.02 \mathrm{~km}$ (Table 1). The low expected frequency of reconstructed queens without any siring males (Fig. 1) indicated that very few colonies remained undetected and, apparently, the queens were able to sample genes from most of the surrounding male-producing colonies. Therefore, the sample of siring males found in each particular colony was a good representation of the number of reproductively active colonies in each location (during the queen's receptive period), thus allowing for the estimation of $N_{\mathrm{e}}{ }^{\prime}$. On average, the effective number of breeding individuals within a queen's mating area was $N_{\mathrm{e}}{ }^{\prime}=16.2 \pm 0.7$ (mean $\pm \mathrm{SE}$; Table 1).

\section{Colony-dependent male fitness component}

None of the reconstructed queens was found to contribute males to more than one colony. On the other hand, the colony mating success was found to be positively correlated with the relative siring success of individual males ( $r_{\mathrm{s}}=0.26 ; n=73$ males; $P=0.025$ ). In other words, the queens that contributed more successfully mated males also produced the males which sired most worker offspring within colonies (Fig. 2). 


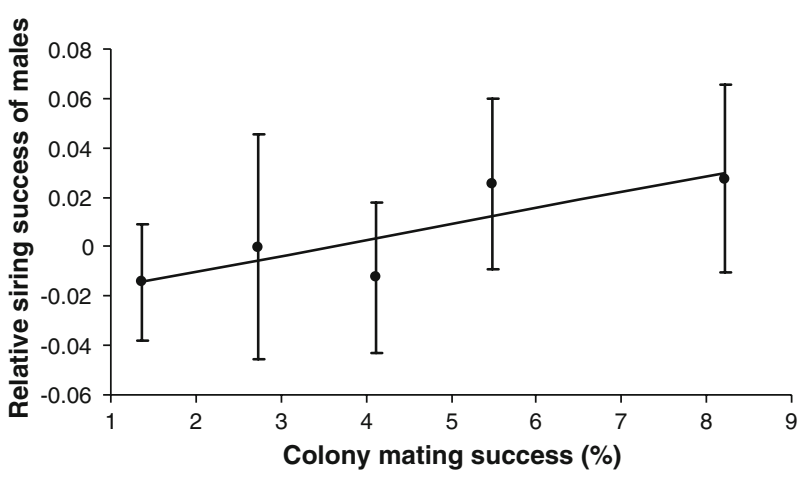

Fig. 2 Overall correlation between colony mating success (proportion of siring males assigned to a specific reconstructed queen in relation to the whole male sample set) and the relative siring success of individual males (obtained from Eq. 4). Only worker offspring unambiguously assigned into a particular patriline were employed in this correlation ( $n=597$ workers). Means and SD are represented by dots and whiskers, respectively

\section{Discussion}

The combination of particular traits, such as restricted queen dispersal and male-biassed sex ratios, with other $N_{\mathrm{e}}$ limiting factors also shared by other hymenopterans (eusociality, haplodiploidy and complementary sex determination) are likely to cause important constraints on $E$. burchellii's effective population size. For instance, based on the E. burchellii census population size and its colony density in Barro Colorado Island (BCI), Chapman and Bourke (2001) estimated a maximal effective population size of 112.5 assuming an infinite level of queen multiple mating. Similar low $N_{\mathrm{e}}$ estimates ( $<100$ individuals) were found in geographically isolated populations of the bumblebee Bombus sylvarum and the wood ant Formica lugubris undergoing bottleneck events (Elis et al. 2006; Mäki-Petäya and Breen 2007). In contrast, our study population showed high heterozygosity, weak population differentiation and no evidence for inbreeding. Moreover, we could demonstrate that, by mating with multiple males, E. burchellii queens are able to sample the genes of males from up to ten different colonies, boosting the effective number of breeding individuals within their mating area.

Eciton burchellii, thus, seems to be capable of maintaining high gene flow via male individuals. For instance, we did not find significant overall genetic differentiation, although the pairwise $F_{\mathrm{ST}}$ values did show weak but significant differentiation between the male samples of two locations (Table 2). This genetic differentiation may reflect different timing in the mating of these queens, which, hence, gathered a different sample of males (none of the reconstructed queens were found to contribute males to more than one colony and single-cohort males were not related to other cohorts of males). In addition, our study population showed high heterozygosity and no evidence for inbreeding. A mild inbreeding was found in the New World army ant Neivamyrmex nigrescens (Kronauer et al. 2007), but evidence for diploid males in army ants is lacking (Kronauer et al. 2006a), suggesting that inbreeding is not common or that single-locus CSD is absent in this group of ants. Additional evidence for a lack of inbreeding and high nuclear gene flow in E. burchellii populations was provided by Berghoff et al. (2008), who showed that different colonies distributed along both sides of the Panama Canal belong to one panmictic population. However, the analysis of mitochondrial DNA revealed high population viscosity. This phenomenon is a mere consequence of the limited dispersal capacity of queens, resulting in a clear disequilibrium between maternal (mitochondrial DNA) and paternal (nuclear DNA) gene flow. Therefore, dispersal in Eciton army ants seems to be strongly male biassed, as shown for other ant species with wingless queens (Chapuisat and Crozier 2001; Doums et al. 2002; Seppä et al. 2006), but also for some species with alate queens (Ross and Shoemaker 1997; Rüppell et al. 2003; Sanetra and Crozier 2003; Sundström et al. 2003). Nevertheless, during their monthly migrations, Eciton colonies are able to cover up to $1.6 \mathrm{~km}$ (Franks 1982) and, hence, queens also contribute, although in a lesser extent, to dispersal.

Flight distance estimations for ant species are very scarce and variable, e.g., ranging between 2 and $10 \mathrm{~km}$ in fire ants (Markin et al. 1971; Vogt et al. 2000). Although direct estimates of male flight distance in army ants are lacking, indirect approximations based on the distance between reproductive colonies lead Schneirla (1971, p. 254) to estimate a minimal flight distance of $300 \mathrm{~m}$. Our results support Schneirla's observations with genetic data. If army ant densities in the Chiapas coastal plain and sierra are different from those found in BCI in Panama (Franks 1982), our flight distance estimates will be directly affected. A higher density will result in an overestimation, whereas a lower density will cause an underestimation of the actual flight distances. Franks (1982) found that E. burchellii has maintained a constant number of about 55 colonies in BCI $\left(3.5\right.$ colonies $\left./ \mathrm{km}^{2}\right)$ for at least 40 years. However, army ant densities can be affected by microclimatic differences, litter depth and composition or availability of bivouac sites (Roberts et al. 2000). Given that our samples were collected in a more disturbed habitat, where secondary forest is separated by patches of agricultural land, one might expect lower population densities in Chiapas than in the undisturbed primary rain forests of the BCI reserve. Our rough estimation of colony density in Chiapas points in that direction. Since flight distance will exponentially increase with decreasing colony density (see Fig. 1 in Chapman et al. 2003), our estimates may, in fact, be quite conservative and constitute a lower limit, 
indicating that males are able to cover distances well over 1 $\mathrm{km}$. The fact that population differentiation was weak between locations separated by $12 \mathrm{~km}$ further corroborates the conservative nature of our flight distance estimation.

Mating systems have a significant influence on the effective population size (Nunney 1993; Sundström et al. 2005; but see Trontti et al. 2007) and multiple mating has been suggested to function as an effective inbreeding avoidance mechanism (Wilson 1963; Packer and Owen 2001; Tarpy and Page 2002). Indeed, by sampling the genes of males from up to ten different colonies, army ant queens are boosting the effective number of breeding individuals within their mating area, thus, maximising gene flow. Our estimated effective number of breeding individuals, however, is likely to be an underestimation because not all queens may contribute males during a given reproductive season and given that queens' generations overlap (Nunney 1993). In addition, we found a significant negative relatedness between the queens and their mates, suggesting that queens are less related than average to their mates. Before gaining access to a queen, E. burchellii males must cross the potentially deadly worker force, ultimately 'choosing' the next fathers of their colony (Schneirla 1971). Franks and Hölldobler (1987) pointed out that if workers are to maximise their own inclusive fitness, they should choose the males that offer the greatest fertility, presumably the more robust ones exhibiting the most queen-like parfumarie. Our results show that workers might also choose males based on their relatedness to the queen, which could also function as an inbreeding avoidance mechanism.

We could demonstrate the existence of a colonydependent male fitness component because those colonies that contributed a larger proportion of successfully mated males to the population (namely, those males which managed to find a foreign colony, be accepted by its worker force and inseminate the queen with fertile sperm) also produced the males which sired most worker offspring within colonies (Fig. 2). The presence of rare mates with a low siring success could be explained through colony-level benefits (Fuchs and Moritz 1999). Interestingly, a similar colony-dependent male fitness component was previously found in the honeybee Apis mellifera (Kraus et al. 2003), another highly polyandrous hymenopteran with extreme male biassed sex ratios. Additionally, honeybee virgin queens were shown to be preferentially reared from rare 'royal' subfamilies, which have extremely low frequencies in the colony's worker force but a high frequency in the queens reared (Moritz et al. 2005). This could also function as a mechanism to maintain rare types in the population (although the paternity shares may change between years). Whether or not army ants also share this queen-determining mechanism with honeybees still remains to be tested, but recent evidence shows that it also occurs in ants (Hughes and Boomsma 2008).

Our results provide a broad insight into the mating and dispersal strategies of Eciton army ants. First, by flying more than $1 \mathrm{~km}$ away from their maternal colonies, males are minimising the chances of mating with related queens. Second, by mating with many unrelated males, Eciton queens boost the effective number of breeding individuals within their mating area. Finally, a further but more limited dispersal of Eciton colonies might be achieved through their monthly migrations, when they are able to cover up to $1.6 \mathrm{~km}$ (Franks 1982). Taking all of these observations together, we conclude that the dispersal and mating system of these army ants seem to enhance gene flow and minimise the deleterious effects associated with small effective population size.

Acknowledgments We thank O. Argüello Najera for assistance in the field, P. Leibe, F. Hesche and D. Kleber for technical support in the laboratory, M. Lattorff for improving earlier versions of this manuscript and the two anonymous referees for their constructive comments. Financial support was provided by a DAAD-FUNDAYACUCHO scholarship (RJ). All samples were collected following the Mexican legal regulations.

\section{References}

Berghoff SM, Kronauer DJC, Edwards KJ, Franks NR (2008) Dispersal and population structure of a New World predator, the army ant Eciton burchellii. J Evol Biol 21:1125-1132. doi: 10.1111/j.1420-9101.2008.01531.x

Boomsma JJ, Ratnieks FLW (1996) Paternity in eusocial Hymenoptera. Philos Trans R Soc B 351:947-975. doi:10.1098/rstb.1996. 0087

Bourke AFG, Franks NR (1995) Social evolution in ants. Princeton University Press, Princeton, NJ

Bourke AFG, Heinze J (1994) The ecology of communal breeding: the case of multiple-queen Leptothoracine ants. Philos Trans R Soc B 345:359-372. doi:10.1098/rstb.1994.0115

Chapman RE, Bourke AFG (2001) The influence of sociality on the conservation biology of social insects. Ecol Lett 4:650-662. doi: 10.1046/j.1461-0248.2001.00253.x

Chapman RE, Wang J, Bourke AFG (2003) Genetic analysis of spatial foraging patterns and resource sharing in bumble bee pollinators. Mol Ecol 12:2801-2808. doi:10.1046/j.1365-294X. 2003.01957.x

Chapuisat M, Crozier RH (2001) Low relatedness among cooperatively breeding workers of the greenhead ant Rhytidoponera metallica. J Evol Biol 14:564-573. doi:10.1046/j.1420-9101. 2001.00310.x

Crozier RH, Pamilo P (1996) Evolution of social insect colonies. Sex allocation and kin selection. Oxford University Press, Oxford

Darvill B, Knight ME, Goulson D (2004) Use of genetic markers to quantify bumblebee foraging range and nest density. Oikos 107:471-478. doi:10.1111/j.0030-1299.2004.13510.x

Denny AJ, Franks NR, Edwards KJ (2004a) Eight highly polymorphic microsatellite markers for the army ant Eciton burchellii. Mol Ecol Notes 4:234-236. doi:10.1111/j.1471-8286.2004.00627.x

Denny AJ, Franks NR, Powell S, Edwards KJ (2004b) Exceptionally high levels of multiple mating in an army ant. Naturwissenschaften 91:396-399. doi:10.1007/s00114-004-0546-4 
Doums C, Cabrera H, Peeters C (2002) Population genetic structure and male-biased dispersal in the queenless ant Diacamma cyaneiventre. Mol Ecol 11:2251-2264. doi:10.1046/j.1365-294X. 2002.01619.x

Elis S, Knight ME, Darvill B, Goulson D (2006) Extremely low effective population sizes, genetic structuring and reduced genetic diversity in a threatened bumblebee species, Bombus sylvarum (Hymenoptera: Apidae). Mol Ecol 15:4375-4386. doi: 10.1111/j.1365-294X.2006.03121.x

Franks NR (1982) A new method for censusing animal populations: the number of Eciton burchelli army ant colonies on Barro Colorado Island, Panama. Oecologia 52:266-268. doi:10.1007/ BF00363847

Franks NR, Hölldobler B (1987) Sexual competition during colony reproduction in army ants. Biol J Linn Soc Lond 30:229-243. doi:10.1111/j.1095-8312.1987.tb00298.x

Fuchs S, Moritz RFA (1999) Evolution of extreme polyandry in the honeybee Apis mellifera L. Behav Ecol Sociobiol 45:269-275

Gadagkar R (1991) On testing the role of genetic asymmetries created by haplodiploidy in the evolution of eusociality in the Hymenoptera. J Genet 70:1-31. doi:10.1007/BF02923575

Gotwald WH Jr (1995) Army ants: the biology of social predation. Cornell University Press, Ithaca

Goudet J (2001) FSTAT, a program to estimate and test gene diversities and fixation indices. FSTAT v2.9.3.2. Home page at: http://www2.unil.ch/popgen/softwares/fstat.htm

Hartl DL, Clark AG (2007) Principles of population genetics. Sinauer, Sunderland

Hedrick PW (2005) A standardized genetic differentiation measure. Evol Int J Org Evol 59:1633-1638

Hedrick PW, Parker JD (1997) Evolutionary genetics and genetic variation of haplodiploids and X-linked genes. Annu Rev Ecol Syst 28:55-83. doi:10.1146/annurev.ecolsys.28.1.55

Hölldobler B, Bartz SH (1985) Sociobiology of reproduction in ants. In: Hölldobler B, Lindauer M (eds) Experimental behavioral ecology and sociobiology. Fischer, Stuttgart, pp 237-257

Hölldobler B, Wilson EO (1990) The ants. Belknap/Harvard University Press, Cambridge

Hughes WOH, Boomsma JJ (2008) Genetic royal cheats in leafcutting ant societies. Proc Natl Acad Sci USA 105:5150-5153. doi:10.1073/pnas.0710262105

Jaffé R, Kronauer DJC, Kraus FB, Boomsma JJ, Moritz RFA (2007) Worker caste determination in the army ant Eciton burchellii. Biol Lett 3:513-516. doi:10.1098/rsbl.2007.0257

Keller L, Passera L (1993) Incest avoidance, fluctuating asymmetry, and the consequences of inbreeding in Iridomyrmex humilis, an ant with multiple queen colonies. Behav Ecol Sociobiol 33:191199. doi:10.1007/BF00216600

Knight ME, Martin AP, Bishop S, Osborne JL, Hale RJ, Sanderson RA, Goulson D (2005) An interspecific comparison of foraging range and nest density of four bumblebee (Bombus) species. Mol Ecol 14:1811-1820. doi:10.1111/j.1365-294X.2005. 02540.x

Konovalov DA, Heg D (2008) A maximum-likelihood relatedness estimator allowing for negative relatedness values. Mol Ecol Resour 8:256-263. doi:10.1111/j.1471-8286.2007.01940.x

Kraus FB, Neumann P, Scharpenberg H, Van Praagh J, Moritz RFA (2003) Male fitness of honeybee colonies (Apis mellifera L.). J Evol Biol 16:914-920. doi:10.1046/j.1420-9101.2003.00593.x

Kraus FB, Koeniger N, Tingek S, Moritz RFA (2005) Using drones for estimating colony number by microsatellite DNA analyses of haploid males in Apis. Apidologie (Celle) 36:223-229. doi: 10.1051/apido:2005010

Kronauer DJC, Schöning C, Pedersen JS, Boomsma JJ (2006a) Male parentage in army ants. Mol Ecol 15:1147-1151. doi:10.1111/ j.1365-294X.2005.02850.x
Kronauer DJC, Berghoff SM, Powell S, Denny AJ, Edwards KJ, Franks NR, Boomsma JJ (2006b) A reassessment of the mating system characteristics of the army ant Eciton burchellii. Naturwissenschaften 93:402-406. doi:10.1007/s00114-0060121-2

Kronauer DJ, Johnson RA, Boomsma JJ (2007) The evolution of multiple mating in army ants. Evol Int J Org Evol 61:413-422. doi:10.1111/j.1558-5646.2007.00040.x

Liautard C, Keller L (2001) Restricted effective queen dispersal at a microgeographic scale in polygynous populations of the ant Formica exsecta. Evol Int J Org Evol 55:2484-2492

Mäki-Petäya H, Breen J (2007) Genetic vulnerability of a remnant ant population. Conserv Genet 8:427-435. doi:10.1007/s10592-0069182-1

Markin GP, Dillier JH, Hill SO, Blum MS, Hermann HP (1971) Nuptial flight and flight ranges of the imported fire ant, Solenopsis saevissima richteri. J Ga Entomol Soc 6:145-150

Moilanen A, Sundström L, Pedersen JS (2004) MateSoft: a program for deducing parental genotypes and estimating mating system statistics in haplodiploid species. Mol Ecol Notes 4:795-797. doi:10.1111/j.1471-8286.2004.00779.x

Moritz RFA, Lattorff HMG, Neumann P, Kraus FB, Radloff SE, Hepburn HR (2005) Rare royal families in honeybees, Apis mellifera. Naturwissenschaften 92:488-491. doi:10.1007/s00114005-0025-6

Moritz RFA, Dietemann V, Crewe RM (2007) Determining colony densities in wild honeybee populations (Apis mellifera) with linked microsatellite DNA markers. J Ins Cons 12:455-459. doi: 10.1007/s10841-007-9078-5

Nielsen R, Tarpy DR, Reeve HK (2003) Estimating effective paternity number in social insects and the effective number of alleles in a population. Mol Ecol 12:3157-3164. doi:10.1046/ j.1365-294X.2003.01994.x

Nunney L (1993) The influence of mating system and overlapping generations on effective population size. Evol Int J Org Evol 47:1329-1341. doi:10.2307/2410151

Packer L, Owen R (2001) Population genetic aspects of pollinator decline. Conserv Ecol 5:4

Pamilo P (1993) Polyandry and allele frequency differences between the sexes in the ant Formica aquilonia. Heredity 70:472-480. doi:10.1038/hdy.1993.69

Pedersen JS, Boomsma JJ (1999) Effect of habitat saturation on the number and turnover of queens in the polygynous ant, Myrmica sulcinodis. J Evol Biol 12:903-917. doi:10.1046/j.1420-9101. 1999.00109.x

Peeters C, Ito F (2001) Colony dispersal and the evolution of queen morphology in social Hymenoptera. Annu Rev Entomol 46:601630. doi:10.1146/annurev.ento.46.1.601

Queller DC, Goodnight KF (1989) Estimating relatedness using genetic markers. Evolution 43:258-275. Relatedness v5.0.8. Home page at: http://www.gsoftnet.us/GSoft.html

Roberts DL, Cooper RJ, Petit LJ (2000) Use of premontane moist forest and shade coffee agroecosystems by army ants in western Panama. Conserv Biol 14:192-199. doi:10.1046/j.1523-1739. 2000.98522.x

Ross KG, Shoemaker DD (1997) Nuclear and mitochondrial genetic structure in two social forms of the fire ant Solenopsis invicta: insights into transitions to an alternate social organization. Heredity 78:590-602. doi:10.1038/hdy.1997.98

Rüppell O, Strätz M, Baier B, Heinze J (2003) Mitochondrial markers in the ant Leptothorax rugatulus reveal the population genetic consequences of female philopatry at different hierarchical levels. Mol Ecol 12:795-801. doi:10.1046/j.1365-294X.2003. 01769.x

Sanetra M, Crozier RH (2003) Patterns of population subdivision and gene flow in the ant Nothomyrmecia macrops reflected in 
microsatellite and mitochondrial DNA markers. Mol Ecol 12:2281-2295. doi:10.1046/j.1365-294X.2003.01900.x

Seppä P, Fernández-Escudero I, Gyllenstrand N, Pamilo P (2006) Obligatory female philopatry affects genetic population structure in the ant Proformica longiseta. Insectes Soc 53:362-368. doi: 10.1007/s00040-006-0882-9

Schneirla TC (1971) Army ants: A study in social organization. WH Freeman, San Francisco

Sundström L, Keller L, Chapuisat M (2003) Inbreeding and sexbiased gene flow in the ant Formica exsecta. Evol Int J Org Evol 57:1552-1561

Sundström L, Seppä P, Pamilo P (2005) Genetic population structure and dispersal patterns in Formica ants-a review. Ann Zool Fenn 42:163-177

Tarpy DR, Page RE (2002) Sex determination and the evolution of polyandry in honey bees (Apis mellifera). Behav Ecol Sociobiol 52:143-150. doi:10.1007/s00265-002-0498-7

Trontti K, Thurin N, Sundström L, Aron S (2007) Mating for convenience or genetic diversity? Mating patterns in the polygynous ant Plagiolepis pygmaea. Behav Ecol 18:298-303. doi:10.1093/beheco/arl083

Van Wilgenburg E, Driessen G, Beukeboom LW (2006) Single locus complementary sex determination in Hymenoptera: an "unintelligent" design? Front Zool 3:1. doi:10.1186/1742-9994-3-1
Vogt JT, Appel AG, West MS (2000) Flight energetics and dispersal capability of the fire ant, Solenopsis invicta Buren. J Insect Physiol 46:697-707. doi:10.1016/S0022-1910(99)00158-4

Walsh PS, Metzger DA, Higuchi R (1991) Chelex 100 as a medium for simple extraction of DNA for PCR-based typing from forensic material. Biotechniques 10:506-513

Wang J (2004) Sibship reconstruction from genetic data with typing errors. Genetics 166:1963-1979. doi:10.1534/genetics.166.4. 1963

Wang J (2005) Estimation of effective population sizes from data on genetic markers. Philos Trans R Soc B 360:1395-1409. doi: 10.1098/rstb.2005.1682

Wilson EO (1963) Social modifications related to rareness in ant species. Evol Int J Org Evol 17:249-253. doi:10.2307/2406469

Wilson EO (1971) The insect societies. Belknap/Harvard University Press, Cambridge

Wright S (1933) Inbreeding and homozygosis. Proc Natl Acad Sci USA 19:411-420. doi:10.1073/pnas.19.4.411

Zayed A (2004) Effective population size in Hymenoptera with complementary sex determination. Heredity 93:627-630. doi: 10.1038/sj.hdy.6800588 